\title{
Pre-analytic factors and initial biomarker levels in community-acquired pneumonia patients
}

\author{
Alexander Kutz ${ }^{1}$, Eva Grolimund ${ }^{1}$, Mirjam Christ-Crain ${ }^{2}$, Robert Thomann ${ }^{3}$, Claudine Falconnier ${ }^{4}$, Claus Hoess $^{5}$, \\ Christoph Henzen ${ }^{6}$, Werner Zimmerli ${ }^{4}$, Beat Mueller ${ }^{1}$, Philipp Schuetz ${ }^{1 *}$ for the ProHOSP Study Group
}

\begin{abstract}
Background: Blood biomarkers are increasingly used to diagnose, guide therapy in, and risk-stratify communityacquired pneumonia (CAP) patients in emergency departments (EDs). How pre-analytic factors affect these markers' initial levels in this population is unknown.

Methods: In this secondary analysis of consecutive ED patients with CAP from a large multicentre antibiotic stewardship trial, we used adjusted multivariate regression models to determine the magnitude and statistical significance of differences in mean baseline concentrations of five biomarkers (procalcitonin [PCT], C-reactive protein [CRP], white blood cells count [WBC], proadrenomedullin [ProADM], copeptin) associated with six pre-analytic factors (antibiotic or corticosteroid pretreatment, age, gender, chronic renal failure or chronic liver insufficiency).

Results: Of 925 CAP patients (median age 73 years, 58.8\% male), 25.5\% had antibiotic pretreatment, 2.4\%, corticosteroid pretreatment, $22.3 \%$, chronic renal failure, $2.4 \%$ chronic liver insufficiency. Differences associated with pre-analytic factors averaged $6.1 \% \pm 4.6 \%$; the three largest statistically significant changes ( $95 \%$ confidence interval) were: $P C T,+14.2 \%$ ( $+2.1 \%$ to $+26.4 \%, p=0.02)$ with liver insufficiency; ProADM,$+13.2 \%(+10.2 \%$ to $+16.1 \%$, $p<0.01)$ with age above median; CRP, $-12.8 \%(-25.4 \%$ to $-0.2 \%, p=0.05)$ with steroid pretreatment. In post hoc sensitivity analyses, reclassification statistics showed that these factors did not result in significant changes of biomarker levels across clinically used cut-off ranges.
\end{abstract}

Conclusions: Despite statistically significant associations of some pre-analytic factors and biomarker levels, a clinically relevant influence seems unlikely. Our observations reinforce the concept of using biomarkers in algorithms with widely-separated cut-offs and overruling criteria considering the entire clinical picture.

Trial registration: Identifier ISRCTN95122877.

Keywords: Community-acquired pneumonia, Blood biomarkers, Procalcitonin, C-reactive protein, White blood cells count, Proadrenomedullin, Copeptin, Pre-analytic factors, Pretreatment

\section{Background}

To improve outcomes in community-acquired pneumonia (CAP), management guidelines emphasize early diagnosis to enable a timely start of appropriate antimicrobial therapy $[1,2]$. For this purpose, circulating levels of biomarkers associated with bacterial infection and inflammation, procalcitonin (PCT), as well as C-reactive protein (CRP) and white blood cells count (WBC), are increasingly considered in the initial assessment of patients with signs or

\footnotetext{
*Correspondence: schuetzph@gmail.com

'University Department of Medicine, Tellstrasse, CH-5001 Kantonsspital Aarau, Switzerland

Full list of author information is available at the end of the article
}

symptoms suggestive of CAP [3-5]. Additionally, biomarkers mirroring disease-related stress, physiological reserve, or both, are more often being used to stratify disease severity and risk of patients with CAP, to aid in triage and in site-of-care decision-making [6-9]. These analytes include proadrenomedullin (ProADM) or copeptin, which are stoichiometrically co-secreted with adrenomedullin or vasopressin, respectively.

Before admission, CAP patients presenting to the emergency department (ED) frequently have received pretreatment with antibiotics or corticosteroids. Further, these patients are often elderly and may have varying degrees of 
kidney or liver dysfunction. Such pre-analytic factors conceivably could affect initial biomarker levels and hence confound assay interpretation or require adjustment in analysing cut-offs. For example, hepatocyte malfunction affects the main site of CRP synthesis, renal failure could lead to accumulation of proteins normally excreted in the urine, and elderly patients might have a suppressed inflammatory response [10].

The presence and magnitude of any differences in concentrations of newer biomarkers that may be associated with pre-analytic factors in patients with CAP is important [11-17]. Previous literature has addressed such associations only in healthy volunteers or critical care patients, populations differing greatly from ED patients with CAP in pretreatment, age, gender composition, comorbidity, and general state $[12-14,18]$.

We therefore sought to characterise in a large, representative, and well-defined CAP cohort the relative differences in initial levels of five widely used diagnostic or prognostic blood biomarkers that were associated with each of six common and potentially important preanalytic factors. We hypothesised that the magnitude and statistical significance of any changes would reflect the clinical relevance of the relationships and the possible need to consider adjusted cut-offs in subgroups in everyday practice. The five blood biomarkers investigated were PCT, CRP, WBC, ProADM, and copeptin, and the six pre-analytic factors were antibiotic or steroid pretreatment, age, gender, chronic renal failure, and chronic liver insufficiency.

\section{Methods}

\section{Patients, setting, ethics}

This secondary analysis included all patients with confirmed CAP from the completed prospective, multicentre, randomised, controlled ProHOSP study [19]. ProHOSP assessed PCT-guided antibiotic stewardship in consecutive adults (age $\geq 18$ years) with presumed lower respiratory infection of $<28$ days' duration presenting to EDs at any of six Swiss secondary or tertiary care, academic or nonacademic hospitals from October 2006 to March 2008 [20].

Patients had to have come from the community or a nursing home with at least one symptom of cough, sputum production, dyspnoea, tachypnoea, or pleuritic pain, plus rales during auscultation or at least one infectious sign (core body temperature $>38.0^{\circ} \mathrm{C}$, shivering, WBC $>10$ or $<4$ cells $\times 10^{9} / \mathrm{L}$ ). CAP was confirmed in all patients by new or increasing radiographic lung infiltrate. Patients were excluded for active intravenous drug abuse, severe immunosuppression other than corticosteroids, imminently life-threatening comorbidity, hospital-acquired pneumonia, or ongoing chronic antibiotic administration. Short-term antibiotic therapy or corticosteroid treatment before presentation did not affect eligibility. Within the trial, patients were stratified by study center and randomised 1:1 to antibiotic administration according to either i) state-of-the-art evidence-based guidelines (controls) or ii) an algorithm recommending antibiotics only when PCT values exceeded previously validated cut-offs [20].

Data on demographics, comorbidities, laboratory and vital parameters, imaging, current and recent medication, and other baseline characteristics were assembled for each patient upon presentation. Antibiotic or steroid pretreatment and comorbidities were identified through one or more of patient self-report, general practitioner notes and medical chart review. We did not collect data on diagnostic procedures such as CT scans performed during the trial, as such exams took place at the discretion of the treating physicians rather than systematically.

Approval for ProHOSP was obtained from all local ethical committees; patients gave written informed consent. ProHOSP was registered in the "Current Controlled Trials Database" (http://www.controlled-trials. com/ISRCTN95122877).

\section{Biomarker measurement}

In all patients, blood specimens for later marker measurement were collected upon admission, i.e., within the first 24 hours post-presentation. CRP concentrations were determined by an enzyme immunoassay (EMIT, Merck Diagnostica, Zürich, Switzerland) having a $<5 \mathrm{mg} / \mathrm{L}$ detection limit. PCT determinations were made using a timeresolved amplified cryptate emission technology-based assay (Kryptor ${ }^{\circ}$ PCT, Thermo Scientific Biomarkers [B R A H M S AG], Hennigsdorf, Germany) with a $0.06 \mu \mathrm{g} / \mathrm{L}$ functional sensitivity [21]. ProADM and copeptin were batch-measured in plasma with sandwich immunoassays (Kryptor ${ }^{\circ}$, Thermo Scientific Biomarkers) with $0.08 \mathrm{nmol} /$ $\mathrm{L}$ and $0.4 \mathrm{pmol} / \mathrm{L}$ analytical detection limits, respectively [15-17,22].

\section{Statistics}

Our primary analysis used linear regression models to investigate the association of each studied pre-analytic factor with the level of each studied biomarker at ED presentation. Due to non-linearity, biomarker values were transformed into deciles before entry into the models. Regression coefficients thus correspond to a decile increase or decrease.

To investigate the potential influence of antibiotic pretreatment on biomarker concentrations, we compared the patients who at ED presentation, had any recent antibiotic exposure, regardless of agent(s), dose(s) or administration route(s), versus the patients without such exposure. For our analysis of the potential impact of corticosteroid pretreatment on biomarker levels, we 
compared patients receiving at least one dose of $\geq 20 \mathrm{mg}$ prednisolone equivalent/day before presentation versus patients without such treatment. This threshold was chosen considering dose levels found to be relevant in prior studies focusing on corticosteroid influence on biomarker release $[14,23]$. To analyse the influence of age, we formed two groups by dichotomising patients according to the median age of the study sample, 73 years. Since the ProHOSP protocol did not call for routine comprehensive evaluation of kidney or liver function at presentation, patients were dichotomised as to whether or not their medical records noted chronic renal failure or chronic liver insufficiency.

Regression models were adjusted for the following covariates: pneumonia severity index (PSI) [24], creatinine (transformed into deciles due to non-linearity), presence of chronic obstructive pulmonary disease (COPD), and presence of diabetes mellitus. The PSI is a well-validated CAP severity/risk scoring system based on a total of 20 sociodemographic variables, comorbidities (neoplasia, congestive heart failure, and hepatic, cerebrovascular or renal disease), and physical, radiographic, and laboratory findings (not including any of our studied biomarkers). Incorporating PSI as a covariate therefore adjusted for the patient's CAP severity and simultaneously, comorbidity and general state. However, to prevent over-adjustment, for the analyses regarding the associations of the respective factors and biomarker levels, we used PSI scores excluding points for age, gender, or renal or hepatic dysfunction-related variables.

We also conducted exploratory analyses examining the influence of each of the six factors of interest on each of the five biomarker concentrations during a 1-week follow-up (day 0 [presentation], 3, 5, and 7 values); methodology is described elsewhere (see Additional file 1). To evaluate the clinical impact of biomarker level changes, in post hoc sensitivity analyses, reclassification statistics were performed (see Additional file 2).

All confidence intervals (CIs) are two-sided; tests were carried out at 5\% significance levels. Analyses were performed with STATA 12.1 (Stata Corp., College Station, TX, USA). Discrete variables are expressed as counts, percentages, or both, and continuous variables are expressed as medians and interquartile ranges (IQRs; $25^{\text {th }}-75^{\text {th }}$ percentiles).

\section{Results}

The study sample comprised all 925 confirmed CAP patients included in the ProHOSP trial. Baseline characteristics are summarised in Table 1. Antibiotic pretreatment was common, administered to just over one-quarter of the study sample, whilst steroid pretreatment was uncommon (2.4\% of patients). Typical of the ED population with CAP, the study sample tended to be elderly and male and had a substantial comorbidity burden, which included chronic
Table 1 Baseline characteristics of the study sample

\begin{tabular}{|c|c|}
\hline Characteristics & All patients $(\mathrm{N}=925)$ \\
\hline \multicolumn{2}{|l|}{ Demographic characteristics } \\
\hline Age, median (IQR), yr. & $73(59-82)$ \\
\hline Male, \% (n) & $58.8 \%(544)$ \\
\hline \multicolumn{2}{|l|}{ Coexisting illnesses, $\%(\boldsymbol{n})^{\mathrm{a}}$} \\
\hline Chronic renal failure & $22.3 \%(206)$ \\
\hline Chronic liver insufficiency & $2.4 \%(22)$ \\
\hline Chronic obstructive pulmonary disease & $30.5 \%(282)$ \\
\hline Diabetes mellitus & $17.5 \%(162)$ \\
\hline Congestive heart failure & $17.2 \%(159)$ \\
\hline \multicolumn{2}{|l|}{ Clinical history, \% (n) } \\
\hline Antibiotic pretreatment ${ }^{a, b}$ & $25.5 \%(236)$ \\
\hline Steroids $\geq 20 \mathrm{mg}$ prednisolone equivalent $/ \mathrm{d}^{\mathrm{a}}$ & $2.4 \%(22)$ \\
\hline Cough & $82.3 \%(761)$ \\
\hline Sputum & $47.2 \%(437)$ \\
\hline Fever & $66.8 \%(618)$ \\
\hline Chill & $32.5 \%(301)$ \\
\hline Dyspnoea & $75.1 \%(695)$ \\
\hline \multicolumn{2}{|l|}{ New York Heart Association class at presentation } \\
\hline I & $9.8 \%(91)$ \\
\hline$\|$ & $27.2 \%(252)$ \\
\hline III & $26.1 \%(241)$ \\
\hline IV & $12.0 \%(111)$ \\
\hline \multicolumn{2}{|l|}{ Clinical findings } \\
\hline Confusion, \% (n) & $8.0 \%(74)$ \\
\hline Rales during auscultation, \% (n) & $68.8 \%(636)$ \\
\hline Pneumonia severity index, median $(\mathrm{IQR})^{c}$ & $92(68-116)$ \\
\hline Respiratory rate, median (IQR), breaths/min & $20(16-25)$ \\
\hline Systolic blood pressure, median (IQR), mmHg & $132(119-148)$ \\
\hline Diastolic blood pressure, median (IQR), $\mathrm{mmHg}$ & $74(65-83)$ \\
\hline Heart rate, median (IQR), beats/min & $95(82-108)$ \\
\hline Body temperature, median (IQR), ${ }^{\circ} \mathrm{C}$ & $38.1(37.2-38.9)$ \\
\hline \multicolumn{2}{|l|}{ Initial laboratory findings, median (IQR) } \\
\hline $\mathrm{PCT}, \mu \mathrm{g} / \mathrm{L}$ & $0.46(0.15-2.66)$ \\
\hline C-reactive protein, mg/dL & $155(75-252)$ \\
\hline White blood cells count, cells $\times 10^{9} / \mathrm{L}$ & $12.1(9-16.4)$ \\
\hline ProADM, nmol/L & $1.2(0.81-1.86)$ \\
\hline Copeptin, pmol/L & $25(12.7-51.1)$ \\
\hline Creatinine, $\mu \mathrm{mol} / \mathrm{L}$ & $89(69-113)$ \\
\hline \multicolumn{2}{|l|}{ Treatment site, \% (n) } \\
\hline Inpatient & $91.2 \%(844)$ \\
\hline
\end{tabular}

$\mathrm{IQR}$, interquartile range; $\mathrm{PCT}$, procalcitonin; ProADM, proadrenomedullin. Due to inclusion criteria for the present analysis, all patients had a history of CAP. ${ }^{a}$ All data on comorbidities and pretreatments were based on patient report and medical chart review.

${ }^{\mathrm{b}}$ Includes patients receiving at least one dose of antibiotics irrespective of agent, regimen or administration route.

'The pneumonia severity index [24] is scored based on 20 sociodemographic, clinical, laboratory, or comorbidity variables. Patients are categorised into 5 classes, with increasing scores and classes denoting worse severity and mortality risk. 
renal failure in a bit over one-fifth of cases, but chronic liver failure in relatively few patients (2.4\%).

Figures 1 and 2 represent graphically, whilst Table 2 lists, adjusted relative differences in initial biomarker concentrations between subgroups with or without the studied pre-analytic factors, and the $95 \% \mathrm{CI}$ of those differences.

\section{PCT}

Adjusted relative differences in mean baseline PCT between those with the studied pre-analytic factors versus those without those factors ranged from $-5.5 \%$ (antibiotic pretreatment) to $14.2 \%$ (chronic liver insufficiency). Older age showed the smallest impact on PCT levels (-0.5\%). Three factors were associated with a significantly different initial mean PCT concentration: antibiotic pretreatment or being male with lower values, and chronic liver insufficiency with a higher value (Figure 1A).

\section{CRP}

For average initial CRP, adjusted relative differences between patients with the studied pre-analytic factors versus their counterparts without these factors ranged from $-12.8 \%$ (steroid pretreatment) to $6.2 \%$ (chronic liver insufficiency). Almost no difference was seen in patients with chronic renal failure $(-0.6 \%)$. The differences in mean baseline CRP were statistically significant for three factors: pretreatment with steroids, older age, or male gender-all were associated with lower levels (Figure 1B).

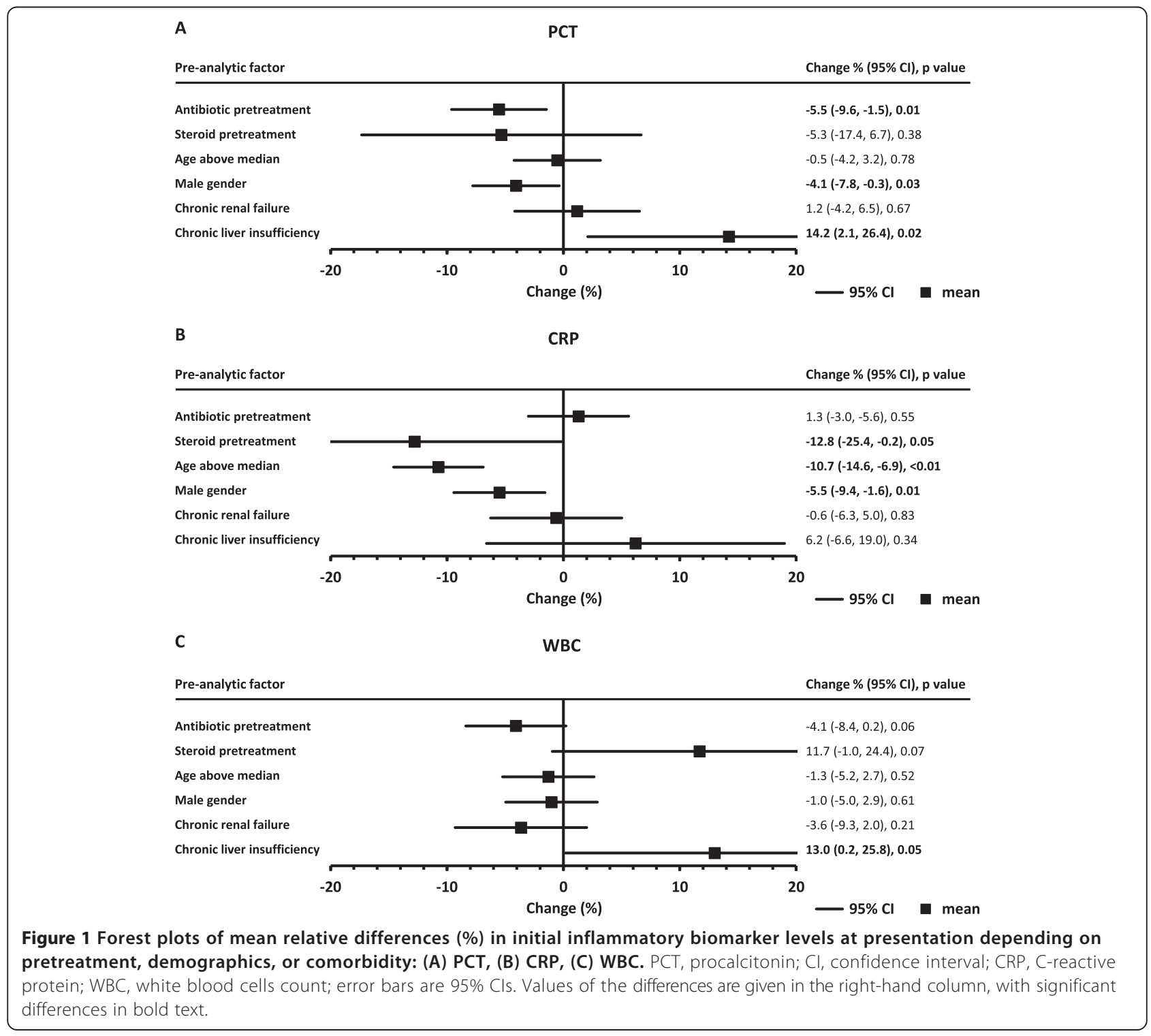




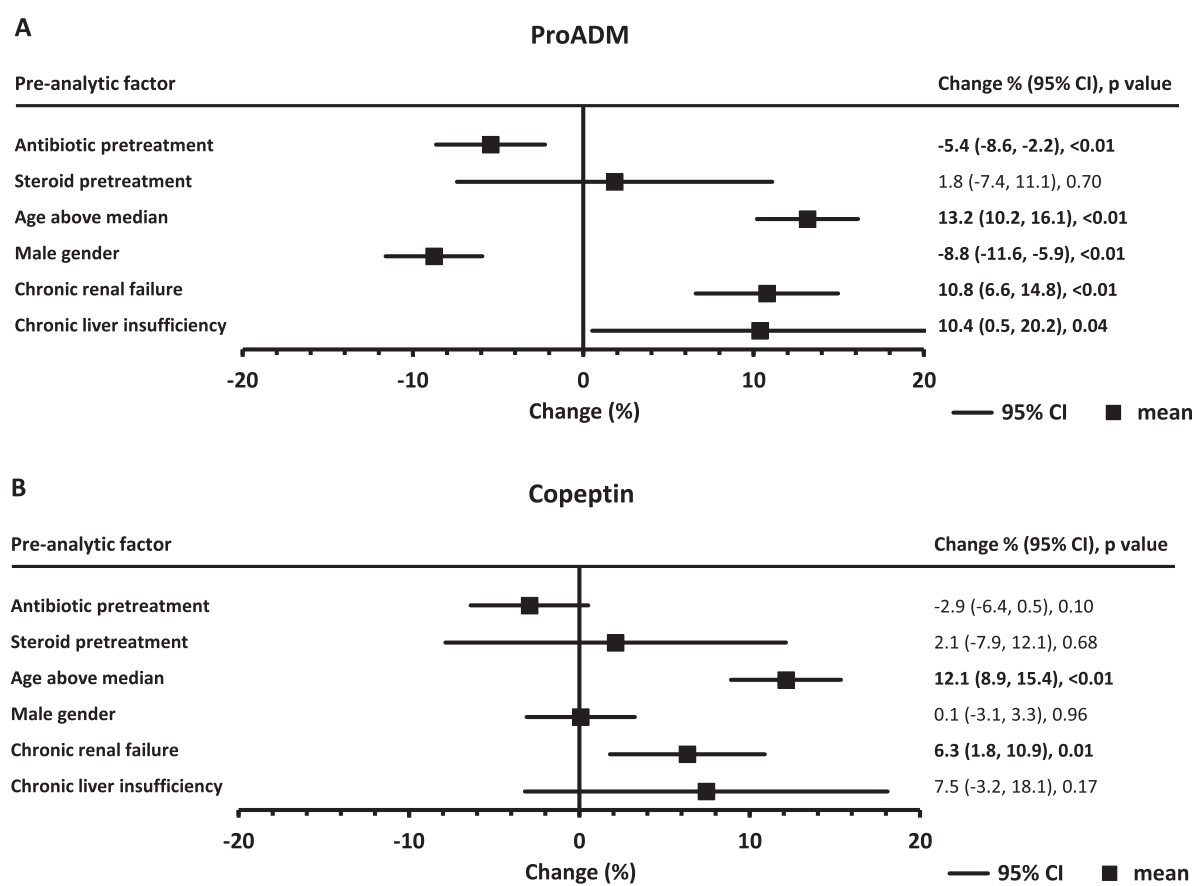

Figure 2 Forest plots of mean relative differences (\%) in initial stress/physiologic reserve biomarker levels at presentation depending on pretreatment, demographics, or comorbidity: (A) ProADM, (B) copeptin. Cl, confidence interval; ProADM, proadrenomedullin; error bars are $95 \% \mathrm{Cls}$. Values of the differences are given in the right-hand column, with significant differences in bold text.

\section{WBC}

Adjusted differences in initial WBC associated with the studied pre-analytical factors varied between $-4.1 \%$ (antibiotic pretreatment) to $13.0 \%$ (chronic liver insufficiency). The smallest difference observed was for male gender $(-1.0 \%)$. Chronic liver failure was associated with significantly elevated mean initial leukocyte count; WBC tended to be lower in patients receiving prior antibiotics and higher in those given prior corticosteroids than in those not administered the respective pretreatment (Figure $1 \mathrm{C}$ ).

\section{ProADM}

The minimum difference in initial ProADM associated with the studied pre-analytic factors was $1.8 \%$ (steroid pretreatment) and the maximum was $13.2 \%$ (older age). Differences were significant for five of six studied factors

Table 2 Adjusted percentage relative change $(95 \% \mathrm{CI})$, initial biomarker concentrations for selected baseline characteristics relative to absence of the characteristic

\begin{tabular}{|c|c|c|c|c|c|c|}
\hline Biomarker & $\begin{array}{c}\text { Antibiotic } \\
\text { pretreatment } \\
(n=236)^{a, b}\end{array}$ & $\begin{array}{c}\text { Steroid } \\
\text { pretreatment } \\
(\mathrm{n}=22)^{\mathrm{a}, \mathrm{c}}\end{array}$ & $\begin{array}{l}\text { Age above study } \\
\text { sample median } \\
\text { (n= 462) }\end{array}$ & $(n=544)$ & $\begin{array}{l}\text { Chronic renal } \\
\text { failure } \\
(n=206)^{a}\end{array}$ & $\begin{array}{l}\text { Chronic liver } \\
\text { insufficiency }^{a} \\
(n=22)^{a}\end{array}$ \\
\hline PCT & $\begin{array}{c}-5.5 \%(-9.6 \% \\
-1.5 \%), \mathbf{p}=\mathbf{0 . 0 1}\end{array}$ & $\begin{array}{c}-5.3 \%(-17.4 \%, 6.7 \%) \\
p=0.38\end{array}$ & $\begin{array}{c}-0.5 \%(-4.2 \%, 3.2 \%) \\
p=0.78\end{array}$ & $\begin{array}{c}-4.1 \%(-7.8 \%,-0.3 \%) \\
\mathbf{p}=\mathbf{0 . 0 3}\end{array}$ & $\begin{array}{c}1.2 \%(-4.2 \%, 6.5 \%) \\
p=0.67\end{array}$ & $\begin{array}{c}14.2 \%(2.1 \% \\
26.4 \%), \mathbf{p}=0.02\end{array}$ \\
\hline CRP & $\begin{array}{c}1.3 \%(-3.0 \%, 5.6 \%) \\
p=0.55\end{array}$ & $\begin{array}{l}-12.8 \%(-25.4 \% \\
-0.2 \%), p=0.05\end{array}$ & $\begin{array}{l}-10.7 \%(-14.6 \% \\
-6.9 \%), p<0.01\end{array}$ & $\begin{array}{c}-5.5 \%(-9.4 \%,-1.6 \%) \\
\mathbf{p}=0.01\end{array}$ & $\begin{array}{c}-0.6 \%(-6.3 \%, 5.0 \%) \\
p=0.83\end{array}$ & $\begin{array}{c}6.2 \%(-6.6 \%, 19.0 \%) \\
p=0.34\end{array}$ \\
\hline WBC & $\begin{array}{c}-4.1 \%(-8.4 \%, 0.2 \%) \\
p=0.06\end{array}$ & $\begin{array}{c}11.7 \%(-1.0 \%, 24.4 \%) \\
p=0.07\end{array}$ & $\begin{array}{c}-1.3 \%(-5.2 \%, 2.7 \%) \\
p=0.52\end{array}$ & $\begin{array}{c}-1.0 \%(-5.0 \%, 2.9 \%) \\
p=0.61\end{array}$ & $\begin{array}{c}-3.6 \%(-9.3 \%, 2.0 \%) \\
p=0.21\end{array}$ & $\begin{array}{c}13.0 \%(0.2 \% \\
25.8 \%), \mathbf{p}=\mathbf{0 . 0 5}\end{array}$ \\
\hline ProADM & $\begin{array}{c}-5.4 \%(-8.6 \% \\
-\mathbf{2 . 2} \%), \mathbf{p}<\mathbf{0 . 0 1}\end{array}$ & $\begin{array}{c}1.8 \%(-7.4 \%, 11.1 \%) \\
p=0.70\end{array}$ & $\begin{array}{c}13.2 \%(10.2 \% \\
16.1 \%), \mathbf{p}<0.01\end{array}$ & $\begin{array}{l}-8.8 \%(-11.6 \% \\
-5.9 \%), p<0.01\end{array}$ & $\begin{array}{c}10.8 \%(6.6 \% \\
14.8 \%), \mathbf{p}<0.01\end{array}$ & $\begin{array}{c}10.4 \%(0.5 \% \\
20.2 \%), \mathbf{p}=0.04)\end{array}$ \\
\hline Copeptin & $\begin{array}{c}-2.9 \%(-6.4 \%,-0.5 \%) \\
p=0.10\end{array}$ & $\begin{array}{c}2.1 \%(-7.9 \%, 12.1 \%) \\
p=0.68\end{array}$ & $\begin{array}{c}12.1 \%(8.9 \%, 15.4 \%) \\
\mathbf{p}<0.01\end{array}$ & $\begin{array}{c}-0.1 \%(-3.1 \%, 3.3 \%) \\
p=0.96\end{array}$ & $\begin{array}{c}6.3 \%(1.8 \%, 10.9 \%) \\
\mathbf{p}=0.01\end{array}$ & $\begin{array}{c}7.5 \%(-3.2 \%, 18.1 \%) \\
p=0.17)\end{array}$ \\
\hline
\end{tabular}

$\mathrm{Cl}$, confidence interval; CRP, C-reactive protein; PCT, procalcitonin; WBC, white blood cells count; ProADM, proadrenomedullin.

Values for baseline factors associated with a statistically significant adjusted relative change in the initial biomarker level are in bold type.

${ }^{a}$ All data on comorbidities and pretreatments were based on patient report and medical chart review.

${ }^{\mathrm{b}}$ Includes patients receiving at least one dose of antibiotics irrespective of agent, regimen, or administration route.

$c^{c} 20 \mathrm{mg} / \mathrm{d}$ prednisolone equivalent. 
(Figure 2A): antibiotic pretreatment or male gender were associated with lower mean ProADM at presentation, whilst increasing age, chronic renal failure, or chronic liver insufficiency were associated with higher ProADM concentrations at that time.

\section{Copeptin}

Changes in baseline copeptin levels associated with the studied factors ranged from $-2.9 \%$ (antibiotic pretreatment) to $12.1 \%$ (older age). Male gender showed the smallest effect $(-0.1 \%)$. The changes attained statistical significance for two factors, increasing age and chronic renal failure, both of which were associated with copeptin elevations (Figure 2B).

\section{Discussion}

The most important and reassuring finding of this secondary analysis was that, despite statistical significance of some associations, none of the six studied preanalytic factors individually seemed to be linked to dramatic relative changes in mean initial levels of any of the five studied biomarkers. The relative differences in baseline biomarker concentration between patients with versus without the factors were statistically significant in 14/30 cases. However, irrespective of whether patients with the pre-analytic factors had elevated or decreased biomarker levels, the 30 differences themselves ranged from $0.1 \%$ to $14.2 \%$ and averaged $6.1 \% \pm 4.6 \%(9.5 \% \pm 3.5 \%$ for the 14 significant differences), and even their $95 \%$ CIs never included a $>27 \%$ change.

These observations support the current concept of using blood biomarkers in validated algorithms with a few widely separated cut-offs, without formal adjustment for pre-analytic factors $[4,6]$. At least regarding antibiotic stewardship in CAP, this concept has proved clearly successful. For example, PCT algorithms developed in clinical trials to recommend or strongly recommend for/ against starting antibiotics in patients presenting to the ED with presumed CAP generally applied PCT cut-offs of $0.1 \mu \mathrm{g} / \mathrm{L}, 0.25 \mu \mathrm{g} / \mathrm{L}$, and $0.5 \mu \mathrm{g} / \mathrm{L}$ [6]; a proposed algorithm for CAP severity/risk classification using ProADM plus a clinical scoring system contains ProADM cut-offs of $0.75 \mathrm{nmol} / \mathrm{L}$ and $1.5 \mathrm{nmol} / \mathrm{L}$ [8,25]. Where higher-risk or higher-severity clinical categories are delineated by a doubling or more in biomarker concentrations, changes of $4.1 \%$ or even $26.4 \%$ (the range in magnitude of significant differences and their 95\% CIs) that may be associated with an individual pre-analytic factor would seem unlikely to produce clinically relevant confounding. This assumption was further evidenced in post-hoc sensitivity analyses, namely reclassification analyses, using different biomarker specific cut-off ranges and estimates from the above-mentioned models (see Additional file 2).
At the same time, our present observations support the concept that biomarker values should not be used in isolation. Rather, these values should be considered in conjunction with the patient's clinical presentation and history, imaging and other laboratory results, etc., as well as in light of the physician's clinical experience and judgment. One way that present biomarker algorithms acknowledge this concept is by including "overruling criteria", i.e., provision to override on a variety of clinical, patient psychosocial, or logistical grounds recommendations based strictly, or largely, on analytic levels $[6,8]$. The overruling criteria could provide a "safety net" in patients presenting with a number of pre-analytic factors that in aggregate, if not individually, might materially affect biomarker levels.

Our results are generally in line with previous observations. For example, Krüger et al. noted lower levels of PCT and WBC but not of CRP in patients with antibiotic pretreatment [11]. Schaaf et al. found slightly decreased admission CRP levels in patients with prior antimicrobial therapy [26]. In our analysis, this association only became significant when considering CRP values during follow-up (see Additional files 1 and 3), perhaps due at least partly to the delayed kinetics of CRP versus PCT. Importantly, the Schaaf study was not adjusted for confounders other than antibiotic pretreatment, which also may help to explain differences with our results. Similar to our observations, two intensive care unit studies found decreased CRP levels after methylprednisolone treatment, reflecting the suppressive effect of corticosteroids on inflammatory markers [12,13]. Remarkably, no such effects on PCT were observed in our study or other studies [12,14]. Additionally, Bruns and colleagues found an influence of inadequate antibiotic treatment on CRP levels [27]. Because in our cohort, we only had an $8 \%$ rate of positive blood cultures, with very few multi-resistant bacteria [28], we were unable to examine this factor.

In older patients, our analysis revealed significantly lower mean initial CRP levels. This finding might be explained by the inverse correlation of inflammatory response and age [10,29].

Renal clearance is one of the PCT elimination pathways [30]. However, the lack of significant change in our investigated inflammatory biomarker levels in patients with chronic renal failure also agrees with earlier results [30-33]. Those data showed that urinary PCT levels were significantly reduced in patients with severe renal dysfunction. However, despite decreased renal elimination, the plasma PCT clearance rate correlated only weakly with renal dysfunction, and thus interpretation of plasma PCT levels should not be confounded by this condition.

In patients with chronic liver insufficiency, we found significantly elevated PCT levels. Similarly, Elefsiniotis et al. 
noted that significant proportions of patients with acute alcoholic hepatitis on a cirrhotic background or with acute on chronic viral hepatitis but without bacterial infection, exhibited serum PCT levels above $0.5 \mu \mathrm{g} / \mathrm{L}$ [34].

We are aware of several limitations of the present work. Firstly, this was a secondary analysis of a previous antibiotic stewardship trial. Therefore, clinical information about pretreatments (dose and duration) and comorbidities were not always systematically collected. Consequently, our analysis dichotomised patients broadly with respect to prior antibiotics or corticosteroids, without considering the type or regimen of these pretreatments. Nevertheless, although data on indications for these modalities were not formally collected, our clinical impression was that antibiotic pretreatment seemed almost always to have represented attempts by general practitioners to address the respiratory infections eventually precipitating the ED visits. Additionally, steroid pretreatment seemed to have been given primarily as therapy for pre-existing COPD. Another disadvantage of the secondary analysis was that chronic renal failure and chronic liver insufficiency were not classified by severity, duration, or aetiology. All these factors may have led to patient misclassification. Additionally, given these limitations to a "pristine" analysis, we did not correct for multiple comparisons or adjust for potential interactions between or among studied pre-analytic factors. Rather, we sought to detect material changes in baseline concentrations of widely used biomarkers associated with key pre-analytic factors whilst adjusting for important potential confounders, namely pneumonia severity and comorbidity. Therefore, synergistic or compensating effects of multiple pre-analytic factors in a given patient cannot be completely excluded based on our results.

Secondly, numbers of patients with prior corticosteroid treatment or chronic liver insufficiency were small $(n=22 / 925$ each), leading to potential under-powering of related analyses. Nonetheless, we consistently observed a stable trend of biomarker values in these subgroups during the 1-week follow-up, a finding that appears to render random fluctuation rather unlikely (see Additional files 1, 3 and 4).

\section{Conclusion}

Each studied pre-analytic factor appeared to be associated with a statistically significant relative change in mean baseline levels of one or more of the examined biomarkers. However, such changes averaged only $6.1 \%$ overall and $9.5 \%$ when statistically significant, and never exceeded $15 \%$, or, with respect to the outer bounds of the $95 \%$ CIs, $27 \%$. Our findings therefore provide reassurance that adjustment for antibiotic or corticosteroid pretreatment, older age, male gender, or chronic renal failure or liver insufficiency are in most cases unlikely to be necessary when biomarkers are used in algorithms containing a few widely separated cut-offs as well as overruling criteria allowing consideration of the entire clinical picture.

\section{Additional files}

Additional file 1: Pre-analytic factors and initial biomarker levels in
community-acquired pneumonia patients - supplementary material.

Additional file 2: Reclassification of inflammatory biomarkers with significant adjusted relative changes for evaluation of clinical impact.

Additional file 3: Mean relative changes (\%) in baseline, day 3, day 5, and day 7 levels of PCT (A), CRP (B) and WBC (C) associated with antibiotic and corticosteroid pretreatment, age, gender, chronic renal failure and chronic liver insufficiency.

Additional file 4: Mean relative changes (\%) in baseline, day 3, day 5, and day 7 levels of ProADM (A) and copeptin (B) associated with antibiotic and corticosteroid pretreatment, age, gender, chronic renal failure and chronic liver insufficiency.

\section{Abbreviations}

CAP: Community-acquired pneumonia; Cl: Confidence interval; COPD: Chronic obstructive pulmonary disease; CRP: C-reactive protein; ED: Emergency department; IQR: Interquartile range; PCT: Procalcitonin; ProADM: Proadrenomedullin; PSI: Pneumonia severity index; WBC: White blood cells count.

\section{Competing interests}

AK, PS, MCC and BM received support from B R A H M S/Thermo Scientific Biomarkers, developer and marketer of PCT, ProADM, and copeptin assays, to attend meetings and fulfill speaking engagements. PS and BM received unrestricted research grants from, and BM has served as a consultant to these firms. All other authors have no relationships to industry relevant to this paper

Neither B R A H M S/Thermo nor any other commercial firm had any involvement in design or conduct of ProHOSP or the present secondary analysis, namely, collection, management, analysis, or interpretation of the data; preparation, review, or approval of manuscripts regarding the results; or decisions on whether and where to submit the manuscripts.

\section{Authors' contributions}

AK, PS, and BM had the idea for and began the analysis, performed the statistical work, and drafted the manuscript. All authors helped to interpret the findings, read and revised the manuscript critically for important intellectual content, and approved the final version of the manuscript

\section{Acknowledgements}

We are grateful to all physicians, nursing staff, and patients participating in ProHOSP and the present secondary analysis. Especially, we thank the staff of the emergency room, medical clinics and central laboratories of the University Hospital Basel, the "Kantonsspitäler" Liestal, Aarau, Luzern and Münsterlingen, and the "Bürgerspital" Solothurn for their very helpful assistance, patience, and technical support. We thank for their participation the ProHOSP Data Safety and Monitoring Board, A.P. Perruchoud, MD, S. Harbarth, MD, and A. Azzola, MD, and the ProHOSP Study Group members other than those among the authors of the present manuscript: Marcel Wolbers, PhD, Isabelle Widmer, MD, Stefanie Neidert, MD, Thomas Fricker, MD, Claudine Blum, MD, Ursula Schild, RN, Katharina Regez, RN, Rita Bossart, RN, Ronald Schoenenberger, MD, Heiner C. Bucher, MD, Ayesha Chaudri, Jeannine Haeuptle, Roya Zarbosky, Rico Fiumefreddo, MD, Melanie Wieland, RN, Charly Nusbaumer, MD, Andres Christ, MD, Roland Bingisser, MD, Kristian Schneider, RN, Christine Vincenzi, RN, Michael Kleinknecht, RN, Brigitte Walz, RN, Verena Briner, MD, Dieter Conen, MD, Andreas Huber, MD, Jody Staehelin, MD, Chantal Bruehlhardt, RN, Ruth Luginbuehl, RN, Agnes Muehlemann, PhD, Ineke lambinon, and Max Zueger, MD. Robert J. Marlowe, Spencer-Fontayne Corporation, Jersey City, NJ, USA, edited this manuscript. 


\section{List of ethical bodies}

EKBB, Ethikkommission beider Basel,

Kantonale Ethikkommission Aargau/Solothurnm,

Ethikkommission des Kantons Luzern,

Ethikkommission des Kantons Thurgau.

\section{Author details}

${ }^{1}$ University Department of Medicine, Tellstrasse, CH-5001 Kantonsspital Aarau, Switzerland. ${ }^{2}$ Department of Internal Medicine, Division of Endocrinology, Diabetes and Clinical Nutrition, University Hospital Basel, Basel, Switzerland. ${ }^{3}$ Department of Internal Medicine, Bürgerspital Solothurn, Solothurn, Switzerland. ${ }^{4}$ Basel University Medical Clinic Liestal, Liestal, Switzerland. ${ }^{5}$ Department of Internal Medicine, Kantonsspital Münsterlingen,

Münsterlingen, Switzerland. ${ }^{6}$ Department of Internal Medicine, Kantonsspital Lucerne, Lucerne, Switzerland.

Received: 9 January 2014 Accepted: 28 October 2014 Published: 15 November 2014

\section{References}

1. Woodhead M, Blasi F, Ewig S, Garau J, Huchon M, Leven M, Ortqvist A, Schaberg T, Torres A, Read R, Verheij TJM: Guidelines for the management of adult lower respiratory tract infections. Clin Microbiol Infect 2011, 17(Suppl. 6):E1-E59.

2. Levy MM, Fink MP, Marshall JC, Abraham E, Angus D, Cook D, Cohen J, Opal SM, Vincent JL, Ramsay G: 2001 SCCM/ESICM/ACCP/ATS/SIS International Sepsis Definitions Conference. Crit Care Med 2003, 31(4):1250-1256.

3. Schuetz P, Briel M, Mueller B: Clinical outcomes associated with procalcitonin algorithms to guide antibiotic therapy in respiratory tract infections. JAMA 2013, 309(7):717-718.

4. Schuetz P, Briel M, Christ-Crain M, Stolz D, Bouadma L, Wolff M, Luyt CE, Chastre J, Tubach F, Kristoffersen KB, Wei L, Burkhardt O, Welte T, Schroeder S, Nobre V, Tamm M, Bhatnagar N, Bucher HC, Mueller B: Procalcitonin to guide initiation and duration of antibiotic treatment in acute respiratory infections: an individual patient data meta-analysis. Clin Infect Dis 2012, 55(5):651-662

5. Christ-Crain M, Muller B: Biomarkers in respiratory tract infections: diagnostic guides to antibiotic prescription, prognostic markers and mediators. Eur Respir J 2007, 30(3):556-573.

6. Schuetz P, Litke A, Albrich WC, Mueller B: Blood biomarkers for personalized treatment and patient management decisions in community-acquired pneumonia. Curr Opin Infect Dis 2013, 26(2):159-167.

7. Kolditz M, Ewig S, Hoffken G: Management-based risk prediction in community-acquired pneumonia by scores and biomarkers. Eur Respir $J$ 2013, 41(4):974-984.

8. Albrich WC, Ruegger K, Dusemund F, Schuetz P, Arici B, Litke A, Blum CA, Bossart R, Regez K, Schild U, Guglielmetti M, Conca A, Schafer P, Schubert M, de Geest S, Reutlinger B, Irani S, Burgi U, Huber A, Muller B: Biomarker-enhanced triage in respiratory infections - a proof-of-concept feasibility trial. Eur Respir $J$ 2013, 42(4):1064-1075.

9. Schuetz $\mathrm{P}$, Wolbers $\mathrm{M}$, Christ-Crain $\mathrm{M}$, Thomann R, Falconnier C, Widmer I, Neidert S, Fricker T, Blum C, Schild U, Morgenthaler NG, Schoenenberger R, Henzen C, Bregenzer T, Hoess C, Krause M, Bucher HC, Zimmerli W, Mueller B: Prohormones for prediction of adverse medical outcome in communityacquired pneumonia and lower respiratory tract infections. Crit Care 2010, 14(3):R106

10. Guertler C, Wirz B, Christ-Crain M, Zimmerli W, Mueller B, Schuetz P: Inflammatory responses predict long-term mortality risk in communityacquired pneumonia. Eur Respir J 2011, 37(6):1439-1446.

11. Kruger S, Ewig S, Kunde J, Hartmann O, Marre R, Suttorp N, Welte T, CAPNETZ study group: Assessment of inflammatory markers in patients with community-acquired pneumonia-influence of antimicrobial pre-treatment: results from the German competence network CAPNETZ. Clin Chim Acta 2010, 411(23-24):1929-1934.

12. Seam N, Meduri GU, Wang H, Nylen ES, Sun J, Schultz MJ, Tropea M, Suffredini AF: Effects of methylprednisolone infusion on markers of inflammation, coagulation, and angiogenesis in early acute respiratory distress syndrome. Crit Care Med 2012, 40(2):495-501.

13. Meduri GU, Golden E, Freire AX, Taylor E, Zaman M, Carson SJ, Gibson M, Umberger R: Methylprednisolone infusion in early severe ARDS: results of a randomized controlled trial. Chest 2007 , 131(4):954-963.
14. de Kruif MD, Lemaire LC, Giebelen IA, Struck J, Morgenthaler NG, Papassotiriou J, Elliott PJ, van der Poll T: The influence of corticosteroids on the release of novel biomarkers in human endotoxemia. Intensive Care Med 2008, 34(3):518-522.

15. Morgenthaler NG, Struck J, Alonso C, Bergmann A: Measurement of midregional proadrenomedullin in plasma with an immunoluminometric assay. Clin Chem 2005, 51(10):1823-1829.

16. Morgenthaler NG, Struck J, Alonso C, Bergmann A: Assay for the measurement of copeptin, a stable peptide derived from the precursor of vasopressin. Clin Chem 2006, 52(1):112-119.

17. Caruhel P, Mazier C, Kunde J, Morgenthaler NG, Darbouret B: Homogeneous time-resolved fluoroimmunoassay for the measurement of midregional proadrenomedullin in plasma on the fully automated system B.R.A.H.M.S KRYPTOR. Clin Biochem 2009, 42(7-8):725-728.

18. Kruger S, Ewig S, Kunde J, Hanschmann A, Marre R, Suttorp N, Welte T: C-terminal provasopressin (copeptin) in patients with communityacquired pneumonia-influence of antibiotic pre-treatment: results from the German competence network CAPNETZ. J Antimicrob Chemother 2009, 64(1):159-162.

19. Schuetz P, Christ-Crain M, Thomann R, Falconnier C, Wolbers M, Widmer I, Neidert S, Fricker T, Blum C, Schild U, Regez K, Schoenenberger R, Henzen C, Bregenzer T, Hoess C, Krause M, Bucher HC, Zimmerli W, Mueller B: Effect of procalcitonin-based guidelines vs standard guidelines on antibiotic use in lower respiratory tract infections: the ProHOSP randomized controlled trial. JAMA 2009, 302(10):1059-1066.

20. Schuetz P, Christ-Crain M, Wolbers M, Schild U, Thomann R, Falconnier C, Widmer I, Neidert S, Blum CA, Schonenberger R, Henzen C, Bregenzer T, Hoess C, Krause M, Bucher HC, Zimmerli W, Müller B, ProHOSP study group: Procalcitonin guided antibiotic therapy and hospitalization in patients with lower respiratory tract infections: a prospective, multicenter, randomized controlled trial. BMC Health Serv Res 2007, 7:102.

21. Christ-Crain M, Jaccard-Stolz D, Bingisser R, Gencay MM, Huber PR, Tamm M, Muller B: Effect of procalcitonin-guided treatment on antibiotic use and outcome in lower respiratory tract infections: cluster-randomised, single-blinded intervention trial. Lancet 2004, 363(9409):600-607.

22. Terzic D, Johansson-Fällgren AS, Ragnarsson O, Goetze JP, Hammarsten O: Evaluation of a sensitive copeptin assay for clinical measurement. Open Clin Chem J 2012, 5:21-26

23. Muller B, Peri G, Doni A, Perruchoud AP, Landmann R, Pasqualini F, Mantovani A: High circulating levels of the IL-1 type II decoy receptor in critically ill patients with sepsis: association of high decoy receptor levels with glucocorticoid administration. J Leukoc Biol 2002, 72(4):643-649.

24. Fine MJ, Auble TE, Yealy DM, Hanusa BH, Weissfeld LA, Singer DE, Coley CM, Marrie TJ, Kapoor WN: A prediction rule to identify low-risk patients with community-acquired pneumonia. N Engl J Med 1997, 336(4):243-250

25. Albrich WC, Dusemund F, Ruegger K, Christ-Crain M, Zimmerli W, Bregenzer T, Irani S, Buergi U, Reutlinger B, Mueller B, Schuetz P: Enhancement of CURB65 score with proadrenomedullin (CURB65-A) for outcome prediction in lower respiratory tract infections: derivation of a clinical algorithm. BMC Infect Dis 2011, 11:112.

26. Schaaf B, Kruse J, Rupp J, Reinert RR, Droemann D, Zabel P, Ewig S, Dalhoff K: Sepsis severity predicts outcome in community-acquired pneumococcal pneumonia. Eur Respir J 2007, 30(3):517-524.

27. Bruns AH, Oosterheert JJ, Hak E, Hoepelman Al: Usefulness of consecutive C-reactive protein measurements in follow-up of severe community-acquired pneumonia. Eur Respir J 2008, 32(3):726-732.

28. Muller F, Christ-Crain M, Bregenzer T, Krause M, Zimmerli W, Mueller B, Schuetz P, Pro HSG: Procalcitonin levels predict bacteremia in patients with community-acquired pneumonia: a prospective cohort trial. Chest 2010, 138(1):121-129.

29. Metlay JP, Schulz R, Li YH, Singer DE, Marrie TJ, Coley CM, Hough L, Obrosky DS, Kapoor WN, Fine MJ: Influence of age on symptoms at presentation in patients with community-acquired pneumonia. Arch Intern Med 1997, 157(13):1453-1459.

30. Meisner M, Schmidt J, Huttner H, Tschaikowsky K: The natural elimination rate of procalcitonin in patients with normal and impaired renal function. Intensive Care Med 2000, 26(Suppl 2):S212-S216.

31. Meisner M, Huttemann E, Lohs T, Kasakov L, Reinhart K: Elimination of procalcitonin and plasma concentrations during continuous veno-venous haemodiafiltration in septic patients. Eur J Anaesthesiol 2000, 17(11):665-671. 
32. Meisner M, Lohs T, Huettemann E, Schmidt J, Hueller M, Reinhart K: The plasma elimination rate and urinary secretion of procalcitonin in patients with normal and impaired renal function. Eur J Anaesthesiol 2001, 18(2):79-87.

33. Meisner M, Huttemann E, Lohs T, Kasakov L, Reinhart K: Plasma concentrations and clearance of procalcitonin during continuous venovenous hemofiltration in septic patients. Shock 2001, 15(3):171-175.

34. Elefsiniotis IS, Skounakis M, Vezali E, Pantazis KD, Petrocheilou A, Pirounaki M, Papatsibas G, Kontou-Kastellanou C, Moulakakis A: Clinical significance of serum procalcitonin levels in patients with acute or chronic liver disease. Eur J Gastroenterol Hepatol 2006, 18(5):525-530.

doi:10.1186/1471-2253-14-102

Cite this article as: Kutz et al:: Pre-analytic factors and initial biomarker levels in community-acquired pneumonia patients. BMC Anesthesiology 2014 14:102.

\section{Submit your next manuscript to BioMed Central and take full advantage of:}

- Convenient online submission

- Thorough peer review

- No space constraints or color figure charges

- Immediate publication on acceptance

- Inclusion in PubMed, CAS, Scopus and Google Scholar

- Research which is freely available for redistribution 